University of New Mexico

UNM Digital Repository

Undergraduate Medical Student Research

Health Sciences Center Student Scholarship

$8-22-2008$

\title{
Post-Endovascular Aneurysm Repair Patient Outcomes and Follow-up Are Not Adversely Impacted By Long Travel Distance to Tertiary Vascular Surgery Centers
}

Dusadee Sarangarm

Mark Langsfeld

John Marek

Follow this and additional works at: https://digitalrepository.unm.edu/ume-research-papers

\section{Recommended Citation}

Sarangarm, Dusadee; Mark Langsfeld; and John Marek. "Post-Endovascular Aneurysm Repair Patient Outcomes and Follow-up Are Not Adversely Impacted By Long Travel Distance to Tertiary Vascular Surgery Centers." (2008). https://digitalrepository.unm.edu/ ume-research-papers/39 


\section{Post-Endovascular Aneurysm Repair Patient Outcomes and Follow-up Are Not Adversely Impacted By Long Travel Distance to Tertiary Vascular Surgery Centers}

Mark Langsfeld, John Marek, Dusadee Sarangarm

University of New Mexico Division of Vascular Surgery, Albuquerque, NM

Objective: To determine if patient adherence to follow-up and patient outcomes after endovascular aneurysm repair (EVAR) are impacted by the distance a patient lives from a tertiary care treatment center.

Methods: A retrospective review of 136 consecutive patients undergoing EVAR at the New Mexico VA Medical Center over a seven year period was conducted. Follow-up occurred with clinic visits and computed tomography scans at one month post-discharge, every six months for two years, and then yearly. Patients were stratified as living within a 100 mile radius of the treatment center (Group 1) versus those living outside this radius (Group 2). Patients were defined as having inadequate follow-up if two or greater consecutive appointments were missed. Survival and graft-related complication rates were analyzed for both patient groups.

Results: Operative mortality was $0.74 \%$ and the overall mean follow-up time was $52.1 \pm 25.9$ months in 136 patients. Ten patients were not analyzed due to mortality less than one year from the EVAR procedure. Of the 126 patients eligible for the study, 19 (15\%) had inadequate followup, as defined by missing two or more appointments. Approximately 44\% (60/136) of patients lived within a 100 mile radius of the treatment center (Group 1) versus 56\% (76/136) of patients living outside this 100 mile radius (Group 2). There was no difference in the adequacy of followup in Group 1 versus Group 2 patients $(14.5 \%$ vs. $13.3 \%, \mathrm{P}=1.0)$. The incidence of major complication defined as aneurysm rupture or conversion to open repair was not statistically different in Group 1 versus Group 2 patients $(5.0 \%$ vs. $11.8 \%, \mathrm{P}=0.23)$. Five patients $(3.7 \%)$ died due to AAA-related late causes (2 in Group 1 vs. 3 in Group 2).

Conclusions: Recent studies have demonstrated higher catastrophic graft complications in patients with inadequate follow-up after EVAR. As many of these procedures are being performed at tertiary referral care centers, many patients are required to travel a long distance for their procedure and follow-up tests. Our study indicates that distance from a tertiary care center is not a limiting factor in patient adherence to follow-up, patient graft-related morbidity or patient survival. 


\section{INTRODUCTION}

Following the introduction of endovascular aneurysm repair (EVAR) by Parodi and associates in 1991, EVAR has become the procedure of choice for many patients for repair of abdominal aortic aneurysms (AAA). ${ }^{1,}$

${ }^{2}$ Currently, four FDA approved endografts are on the market: Medtronic AneuRx (Minneapolis, Minn), Gore Excluder (Flagstaff, Ariz), Endologix PowerLink (Irvine, Calif) and Cook Zenith (Bloomington, Ind).

Reported advantages of the endovascular approach as compared to traditional open repair are reduced blood loss, shorter hospital stays, increased likelihood of discharge to home, less cardiovascular morbidities and decreased peri-operative mortality. ${ }^{3-8}$ Concerns regarding this procedure include a substantial increase in healthcare costs, with questionable long-term benefits in mortality, morbidity and quality of life. ${ }^{9-15}$ Moreover, EVAR has been shown to have a higher rate of graft-related complications which require reintervention compared to open repair. ${ }^{16-18}$ Due to this high rate of reintervention, endograft patients must be monitored for life with radiologic studies, thus emphasizing the critical importance of long-term follow-up for this patient population.

Though clinical trials have shown EVAR and open repair to have comparable outcomes, these trials are performed under conditions that are unlikely to be achieved in general surgical practice. Resources available at a tertiary care center in a clinical trial setting, such as specially recruited research nurses and staff to ensure the completeness of patient follow-up, are frequently unavailable to surgeons in private practice. This raises concerns regarding the completeness of follow-up for the majority of AAA patients and thus, the success of EVAR in terms of long-term patient outcomes. A recent study has shown that post-EVAR patients with incomplete follow-up have higher fatal complication rates in comparison to patients with frequent follow-up. ${ }^{19}$

Given the significance of follow-up for EVAR patients, it is imperative to understand the factors which impede good adherence to follow-up regimens. Studies into the determinants of patient adherence have shown them to be multi-factorial and inconsistent. Some causes of poor patient adherence include patient lack of understanding, inability to comply due to financial, physical or physiologic reasons, long waiting times at clinics and long times between appointments. ${ }^{20,}{ }^{21}$ For our local VA Medial Center (VAMC), patients are referred from rural areas in three surrounding states for treatment of AAA's, thus raising concerns for potential poor patient follow-up due to the long distances patients must travel. The purpose of our study was to test the following hypotheses in a VA patient population:

- Follow-up adherence post-EVAR is superior for patients living close to the VAMC than for those traveling long distances.

- Outcomes for patients with incomplete follow-up are inferior to patients with complete follow-up.

- Outcomes for patients living within $100 \mathrm{mi}$ of Albuquerque are better than for patients living outside of this radius.

\section{METHODS}

Our hypotheses were tested by retrospectively reviewing the results of 136 consecutive EVAR's performed at the Albuquerque VAMC from October, 1999 to April, 2006. Of these 136 patients, 126 patients survived the first year after EVAR and were therefore eligible for follow-up. Thus, data for the group of 126 patients was used for follow-up analyses, while data for the entire series was used for the analyses of distance from Albuquerque. Table I and II summarize the demographics of the entire series and of the 126 patients who were eligible for follow- 
Table I: Demographics for the 136 patients in the series

\begin{tabular}{|c|c|}
\hline Demographics & Value, $r$ \\
\hline Age (median \pm SD) & $72 \pm 7.7$ \\
\hline $\mathrm{AAA}$ size $($ mean $\pm \mathrm{SD})$ & $5.7 \pm 1$ \\
\hline $\begin{array}{l}\text { Patients living within } 100 \mathrm{mi} \\
\text { of Albuquerque }\end{array}$ & $44.1 \%$ \\
\hline Treated emergently & 6 \\
\hline Treated electively & 130 \\
\hline $\begin{array}{l}\text { Treated in industry sponsored } \\
\text { clinical trial }\end{array}$ & 12 \\
\hline Treated in routine practice & 114 \\
\hline \multicolumn{2}{|l|}{ Prosthesis used } \\
\hline AneuRx ${ }^{*}$ & 115 \\
\hline Ancure $^{¥}$ & 13 \\
\hline Excluder $^{\dagger}$ & 7 \\
\hline Endologix & 1 \\
\hline \multicolumn{2}{|c|}{ *Medtronic AneuRx (Minneapolis, Minn } \\
\hline \multicolumn{2}{|c|}{$¥$ ¥Guidant Ancure (Indianapolis, Ind) } \\
\hline \multicolumn{2}{|l|}{ †Gore Excluder (Flagstaff, Ariz) } \\
\hline tEndologix PowerLink (Irvine, & \\
\hline
\end{tabular}

Table II: Demographics of follow-up eligible patients

\begin{tabular}{ll}
\hline Demographics & Value, $n$ \\
\hline Age (median \pm SD) & $71 \pm 7.8$ \\
AAA size (mean \pm SD) & $5.7 \pm 1.1$ \\
$\begin{array}{l}\text { Patients living within 100mi } \\
\text { of Albuquerque }\end{array}$ & $43.7 \%$ \\
Treated emergently & 6 \\
Treated electively & 120 \\
$\begin{array}{l}\text { Treated in industry sponsored } \\
\text { clinical trial }\end{array}$ & 11 \\
Treated in routine practice & 115 \\
Prosthesis used & 112 \\
\multicolumn{1}{c}{ AneuRx } \\
\multicolumn{2}{c}{ Ancure }
\end{tabular}

up, respectively.

All patients who were symptomatic or whose aneurysms were $>5 \mathrm{~cm}$ were evaluated for repair. Patients with favorable anatomy including a proximal infrarenal neck $\geq 15 \mathrm{~mm}$; an aortic neck luminal diameter $\leq 26 \mathrm{~mm}$; aortic angulation $\leq 60^{\circ}$; and common iliac arteries without excessive tortuosity for proximal and distal fixation of an endograft were offered EVAR. Female patients were excluded from the study due to low sample size; only one female patient was treated during the study period. Procedures were performed using a bilateral, transfemoral approach, with intravascular ultrasound and angiography to confirm technically successful graft placement. Attending physician preference determined the type of graft used. All procedures were performed by fellowship trained vascular surgeons in an endovascular operating room suite with fixed imaging.

At the time of their procedure, all patients were prospectively enrolled in a vascular database. Starting in 1999, our VA started participating in the OVER trial (Open versus Endovascular Repair), a national VA study comparing open vs. EVAR repair of abdominal aneurysms. Of note, the postoperative follow-up regimen was the similar for both study and non-study patients, thereby reducing the statistical effects of this confounding factor. Both groups of patients were followed by the same research nurse, who coincidently managed both study patients and non-study patients.

For all patients, missed appointments were documented in the VAMC electronic database and were rescheduled by a research nurse. If verbal contact via telephone was not made, several telephone messages were left regarding the missed appointment and need to reschedule. If repeated telephone attempts failed to reach the patient, a letter was mailed to the permanent home address listed in the VAMC electronic database. If this method of contacting the patient was unsuccessful, no 
further attempt was made to contact the patient directly. At this point, a note was entered into the electronic record to contact the Albuquerque vascular group should anyone in the VAMC system make contact with the patient. Follow-up did differ, however, in that the management of study patients included more frequent telephone contact and stricter monitoring of follow-up compliance when compared to non-study patients.

All patients were followed with an office visit and imaging at one month, every six months for two years and then yearly for life. The imaging modalities used were plain abdominal radiographs (flat, upright, lateral and oblique) and computed tomography (CT) with angiography; duplex ultrasound or noncontrast CT were utilized in place of CT with angiography when patient comorbidities (i.e. renal insufficiency) prohibited the use the contrast. The need for consistent follow-up and the risks associated with EVAR were stressed to each patient before discharge by staff and the attending physician.

For the purposes of this study, we defined incomplete follow-up as any patient who missed more than two consecutive follow-up office visits at the Albuquerque VAMC. All other patients were defined as having frequent follow-up. We also arbitrarily assigned patients living "close" to the VAMC as within a 100mi radius, and those living far as outside this radius. Next, we retrospectively reviewed the electronic charts of all 126 patients to determine their follow-up status. Electronic charts at not only the Albuquerque VAMC, but also at remote VAMC's throughout the United States were reviewed. This resulted in reestablishment of contact with all but five of the 19 patients lost to follow-up. In the absence of definitive evidence of mortality or known complications, these five patients were included in the analysis and assumed to be alive and complication free.

The outcomes examined in our study were overall survival, subsequent need for minor surgical reintervention (all surgical interventions excluding conversion to open repairs) and subsequent need for major reintervention, defined as conversion to open repair.

To calculate survival time and time to initial minor reintervention, Kaplan-Meir life table analyses were performed. Log-rank tests were used to assess the difference between these curves. Differences in distributions were assessed using Wilcoxon Rank Sum test and differences in categorical variables were assessed using Fisher's Exact test. Data was analyzed using SAS 9.1 software (SAS, Inc, Cary, NC). P values $<0.05$ were considered indicative of statistical significance.

\section{RESULTS}

The overall mean follow-up time for the series was $52.1 \pm 25.9$ months; the median was 52.9 months with a minimum of 2 days and a maximum of 94.5 months. No patients had EVAR less than one year at the conclusion of this study. For the entire series, 34 patients required 52 minor surgical reinterventions (angio, $\mathrm{n}=8$; coiling for Type II endoleak, $\mathrm{n}=$ 16; proximal/distal cuff, $\mathrm{n}=13$; stent, $\mathrm{n}=3$, bypass, $\mathrm{n}=4$; miscellaneous interventions, $\mathrm{n}=$ 8), 12 patients required major surgical reintervention defined as conversion to open repair and one patient needed conversion to open repair, but declined the procedure. The types of devices used and major complications by device are summarized in Table III.

Of the patients who underwent open repair subsequent to EVAR, three resulted in death. Two open repair patients experienced incomplete follow-up at the Albuquerque VAMC, one declined follow-up and the other relocated; both patients were repaired at an outside facility and survived their open repair. Additionally, both also lived outside a 100mi radius of Albuquerque. Table IV summarizes the patients who required conversion to open repair and their outcomes. 
Table III: Types of devices and number of complications by device

\begin{tabular}{|c|c|c|c|c|c|}
\hline & \multicolumn{2}{|c|}{ Follow-up, n (\%) } & \multirow{2}{*}{$\begin{array}{l}<100 \text { mi of VAMC, } \\
n(\%)\end{array}$} & \multirow{2}{*}{$\begin{array}{l}>100 \text { mi of VAMC, } \\
n(\%)\end{array}$} & \multirow{2}{*}{$\begin{array}{l}\text { Open conversion, } \\
n(\%)\end{array}$} \\
\hline & Frequent & Incomplete & & & \\
\hline Patient total & 107 & 19 & 60 & 76 & 12 \\
\hline AneuRx ${ }^{*}$ & $89(83.2)$ & $18(94.7)$ & 49 (81.7) & $66(86.8)$ & $10(83.3)$ \\
\hline Ancure ${ }^{¥}$ & $12(11.2)$ & $1(5.3)$ & $6(10.0)$ & $7(9.2)$ & $1(8.3)$ \\
\hline Excluder $^{\dagger}$ & $5(5.7)$ & $0(0.0)$ & $5(8.3)$ & $2(2.6)$ & $1(8.3)$ \\
\hline Endologix & $1(0.9)$ & $0(0.0)$ & $0(0.0)$ & $1(1.3)$ & $0(0.0)$ \\
\hline
\end{tabular}

*Medtronic AneuRx (Minneapolis, Minn)

$¥$ Guidant Ancure (Indianapolis, Ind)

$\dagger$ Gore Excluder (Flagstaff, Ariz)

†Endologix PowerLink (Irvine, Calif)

Table IV: Major complications

\begin{tabular}{|c|c|c|c|c|c|c|}
\hline Complications & $\begin{array}{l}\text { Months after } \\
\text { EVAR }\end{array}$ & Intervention & $\begin{array}{l}\text { Location of } \\
\text { Reintervention }\end{array}$ & $\begin{array}{l}\text { Follow-up } \\
\text { Status }\end{array}$ & $\begin{array}{l}\text { Reason for } \\
\text { Incomplete } \\
\text { Follow-up }\end{array}$ & Outcome \\
\hline $\begin{array}{l}\text { RUPTURED L } \\
\text { EXTERNAL ILIAC }\end{array}$ & 0 & Open & $\begin{array}{l}\text { Albuquerque } \\
\text { VAMC }\end{array}$ & Frequent & & Death \\
\hline POST-OP OCCLUSION & 1 & Open & $\begin{array}{l}\text { Albuquerque } \\
\text { VAMC }\end{array}$ & Frequent & & Survived \\
\hline INFECTED GRAFT & 12 & Open & $\begin{array}{l}\text { Albuquerque } \\
\text { VAMC }\end{array}$ & Frequent & & Survived \\
\hline EXPANDING AAA & 25 & Open & $\begin{array}{l}\text { Albuquerque } \\
\text { VAMC }\end{array}$ & Frequent & & Survived \\
\hline INFECTED GRAFT & 32 & Open & $\begin{array}{l}\text { San Antonio } \\
\text { VAMC }\end{array}$ & Incomplete & DECLINED & Survived \\
\hline RUPTURED AAA & 45 & Open & $\begin{array}{l}\text { Albuquerque } \\
\text { VAMC }\end{array}$ & Frequent & & Death \\
\hline GRAFT MIGRATION & 48 & Open & $\begin{array}{l}\text { Albuquerque } \\
\text { VAMC }\end{array}$ & Frequent & & Survived \\
\hline RUPTURED AAA & 50 & Open & $\begin{array}{l}\text { Albuquerque } \\
\text { University } \\
\text { Hospital }\end{array}$ & Frequent & & Survived \\
\hline $\begin{array}{l}\text { ENLARGING } \\
\text { PROXIMAL AAA }\end{array}$ & 69 & Open & $\begin{array}{l}\text { Albuquerque } \\
\text { VAMC }\end{array}$ & Frequent & & Survived \\
\hline $\begin{array}{l}\text { ILIAC PERF DURING } \\
\text { ATTEMPTED } \\
\text { PLACEMENT OF RIGHT } \\
\text { ILIAC STENT GRAFT }\end{array}$ & 79 & Open & $\begin{array}{l}\text { Albuquerque } \\
\text { VAMC }\end{array}$ & Frequent & & Death \\
\hline ENLARGING AAA & unknown* & Open & $\begin{array}{l}\text { Lubbock } \\
\text { VAMC }\end{array}$ & Frequent & & Survived \\
\hline RUPTURED AAA & unknown* & Open & Dallas VAMC & Incomplete & RELOCATED & Survived \\
\hline
\end{tabular}

*Unable to determine the exact date of operation in electronic chart. 
Table V: AAA-related mortality

\begin{tabular}{lllll}
\hline Mechanism & $\begin{array}{l}\text { Months after } \\
\text { EVAR }\end{array}$ & $\begin{array}{l}\text { Follow-up } \\
\text { status }\end{array}$ & $\begin{array}{l}\text { Location of } \\
\text { residence at } \\
\text { time of EVAR }\end{array}$ & $\begin{array}{l}\text { Miles from } \\
\text { Albuquerque }\end{array}$ \\
\hline $\begin{array}{l}\text { COMPLICATIONS OF CIRRHOSIS, LEADING TO } \\
\text { COAGULOPATHY WITH CONSEQUENT ENDOLEAK }\end{array}$ & 12.69 & FREQUENT & $\begin{array}{l}\text { ALBUQUERQUE, } \\
\text { NM }\end{array}$ & 0 \\
$\begin{array}{l}\text { COMPLICATIONS OF OPEN REPAIR OF INFECTED ELG } \\
\text { COMPLICATIONS OF RIGHT LOWER EXTREMITY }\end{array}$ & 13.25 & FREQUENT & BIG SPRING, TX & 416 \\
$\begin{array}{l}\text { ISCHEMIA WITH THROMBOSIS OF RIGHT LIMB OF } \\
\text { ENDOGRAFT }\end{array}$ & 2.37 & FREQUENT & LOS LUNAS, NM & 23 \\
$\begin{array}{l}\text { PERI-OPERATIVE COMPLICATIONS OF EVAR } \\
\begin{array}{l}\text { COMPLICATIONS OF TRACHEOTOMY STATUS POST } \\
\text { CONVERSION TO OPEN REPAIR }\end{array}\end{array}$ & 0.07 & FREQUENT & $\begin{array}{l}\text { ALBUQUERQUE, } \\
\text { NM }\end{array}$ & 0 \\
\end{tabular}

Five patients died due to AAA-related causes $(3.7 \%)$, three of whom required open repair subsequent to EVAR and died from complications thereof. One patient died within one month of EVAR. None of these patients experienced incomplete follow-up. Three patients lived outside of Albuquerque. Table V delineates the cause of death for each case

According to the study definition, 107 $(85.0 \%)$ of 126 patients achieved frequent follow-up, and $19 \quad(15.0 \%)$ received incomplete follow-up. After one year, the mean follow-up for the 107 patients in the frequent follow-up group was $41.4 \pm 23.0$ months, while the mean follow-up in the incomplete follow-up group was $57.5 \pm 19.7$ months $(\mathrm{P}=0.004)$. For the incomplete follow-up group, the median month of the first missed appointment was $36 \pm 19.0$ months with a minimum of one month and a maximum of 60 months. Most patients in the incomplete follow-up group underwent EVAR during 2000-2002, while patients in the frequent follow-up group are more evenly distributed in time (Table VI). Five of the 19 patients who experienced incomplete follow-up were not seen subsequently at another VA with CT imaging of their AAA. One patient (Patient $\# 50$ ) in the study failed to keep at least one follow-up appointment due to a psychiatric condition. Table VII summarizes the patients in the incomplete follow-up group and their follow-up status within the VAMC system.
Table VI: Distribution of patients by year of EVAR and follow-up status

\begin{tabular}{lll}
\hline EVAR year & $\begin{array}{l}\text { Frequent follow- } \\
\text { up }\end{array}$ & $\begin{array}{l}\text { Incomplete } \\
\text { follow-up }\end{array}$ \\
\hline 1999 & 8 & 1 \\
2000 & 31 & 7 \\
2001 & 27 & 3 \\
2002 & 9 & 6 \\
2003 & 14 & 1 \\
2004 & 20 & 1 \\
2005 & 6 & 0 \\
2006 & 26 & 0 \\
\hline Total & 117 & 19
\end{tabular}

The mean follow-up time for patients living within 100mi of Albuquerque was not statistically different from those living outside a $100 \mathrm{mi}$ radius at $(53.7 \pm 28.3$ months vs. 50.9 \pm 24.0 months; $\mathrm{P}=0.47$ ). Frequent follow-up was achieved in $52(86.7 \%)$ of the 60 patients living within $100 \mathrm{mi}$ of Albuquerque, while eight $(13.3 \%)$ patients received incomplete follow-up. Of the 76 patients living outside a $100 \mathrm{mi}$ radius of Albuquerque, 65 (85.5\%) achieved frequent follow-up and 11 (14.5\%) experienced incomplete follow-up. There was no difference in the percentage of incomplete follow-up patients for those living close vs. those living far $(\mathrm{P}=1.0)$. For the 11 patients living outside a $100 \mathrm{mi}$ radius of Albuquerque who experienced incomplete follow-up, only 
Table VII: Incomplete follow-up patients

\begin{tabular}{|c|c|c|c|c|c|c|}
\hline $\begin{array}{l}\text { Patient } \\
\#\end{array}$ & $\begin{array}{l}\text { Location of residence at } \\
\text { time of EVAR }\end{array}$ & $\begin{array}{l}\text { Miles from } \\
\text { Albuquerque }\end{array}$ & $\begin{array}{l}\text { Months after EVAR of } \\
\text { first missed appointment }\end{array}$ & $\begin{array}{l}\text { Reason for incomplete } \\
\text { follow-up }\end{array}$ & $\begin{array}{l}\text { Seen at } \\
\text { another VAMC }\end{array}$ & $\begin{array}{l}\text { Months before AAA size } \\
\text { documented at another VAMC }\end{array}$ \\
\hline 3 & ALBUQUERQUE, NM & 0 & 3 & NON-COMPLIANT & YES & 29 \\
\hline 10 & ALBUQUERQUE, NM & 0 & 30 & RELOCATED & YES* & \\
\hline 17 & ALBUQUERQUE, NM & 0 & 36 & DECLINED & NO & \\
\hline 20 & COLORADO CITY, TX & 434 & 42 & MEDICAL & NO & \\
\hline 27 & BORGER, TX & 340 & 30 & RELOCATED & YES* & \\
\hline 30 & ALBUQUERQUE, NM & 0 & 48 & NON-COMPLIANT & NO & \\
\hline 32 & MIDLAND, TX & 413 & 48 & DECLINED & YES & 24 \\
\hline 35 & SANTA FE, NM & 64 & 36 & RELOCATED & YES & 0 \\
\hline 50 & ALBUQUERQUE, NM & 0 & 1 & PSYCHIATRIC & NO & \\
\hline 60 & MUNDS PARK, AZ & 341 & 66 & DECLINED & YES* & \\
\hline 67 & AMARILLO, TX & 287 & 36 & RELOCATED & YES* & \\
\hline 83 & FOUNTAIN, CO & 366 & 3 & RELOCATED & YES* & \\
\hline 86 & SUNRAY, TX & 311 & 42 & RELOCATED & YES & 12 \\
\hline 88 & SAN ANGELO, TX & 502 & 12 & DECLINED & YES & 18 \\
\hline 89 & AMARILLO, TX & 287 & 42 & FINANCIAL/BENEFITS & NO & \\
\hline 91 & ALBUQUERQUE, NM & 0 & 12 & RELOCATED & YES* & \\
\hline 92 & ODESSA, TX & 402 & 54 & MEDICAL & YES* & \\
\hline 103 & ALBUQUERQUE, NM & 0 & 12 & FINANCIAL/BENEFITS & YES* & \\
\hline 128 & AMARILLO, TX & 287 & 18 & MEDICAL & YES & 0 \\
\hline
\end{tabular}

*Documented CT imaging at another VA, but no record of AAA size

two were not subsequently seen at another VAMC with CT imaging of their AAA's. The closest of these 11 patients to the Albuquerque VAMC was $287 \mathrm{mi}$ and the furthest was $502 \mathrm{mi}$. For the eight patients living within a $100 \mathrm{mi}$ radius of Albuquerque who experienced incomplete follow-up, seven lived within Albuquerque and one lived $64 \mathrm{mi}$ from Albuquerque.

Comparing the outcomes of patients living within and outside $100 \mathrm{mi}$ radius of Albuquerque, no statistical difference was found in survival (Fig 1) or rate of reintervention (Fig 3). The incidence 


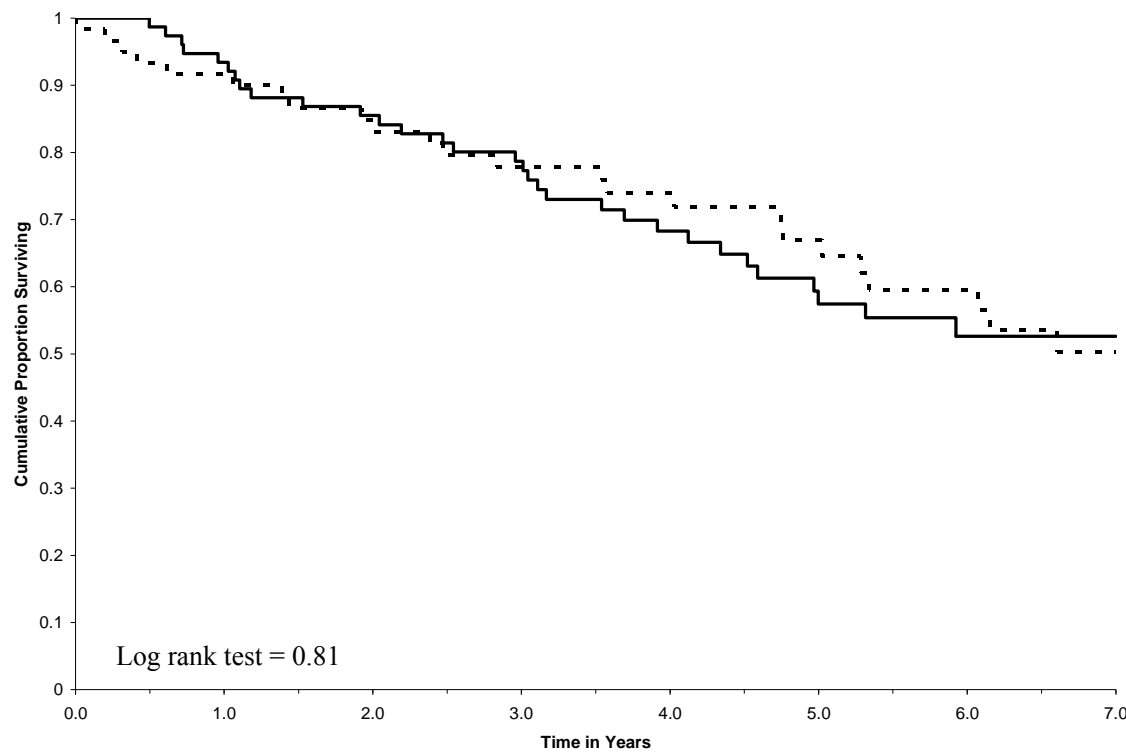

Fig 1: Survival for patients living outside a 100mi radius of Albuquerque (solid line) vs. those living within a 100mi radius of Albuquerque (dashed line)

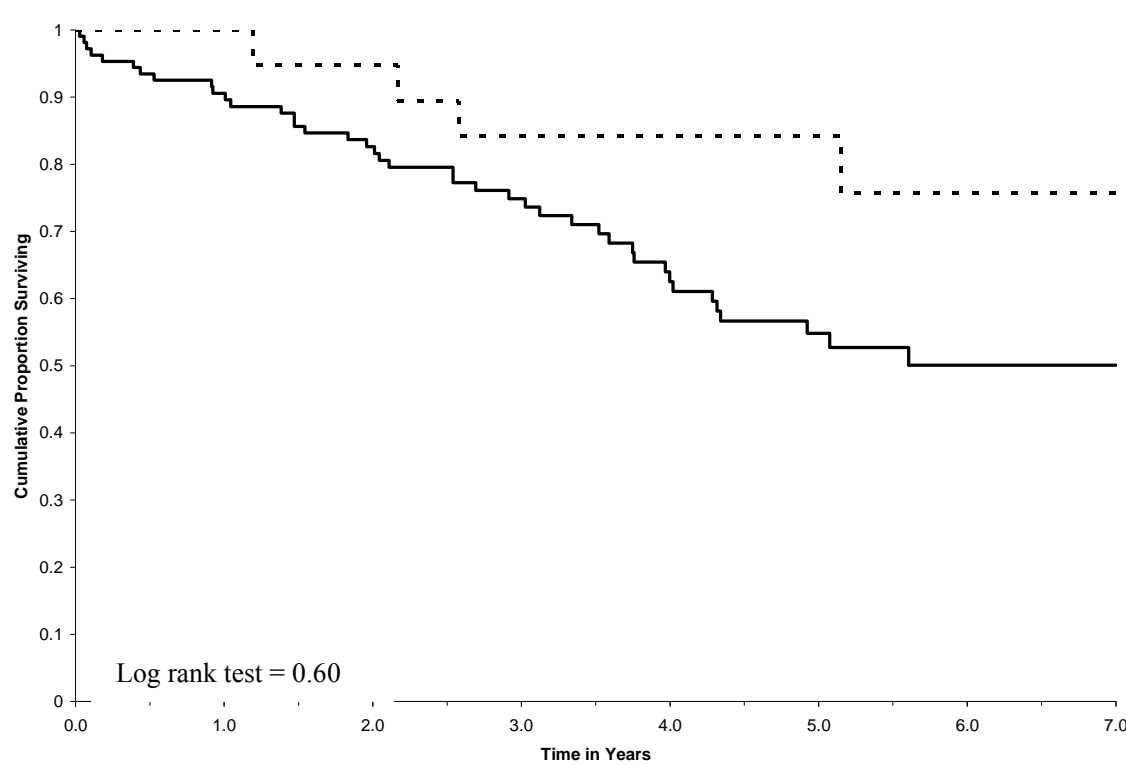

Fig 2: Survival for patients with frequent follow-up (solid line) vs. those with incomplete follow-up (dashed line)

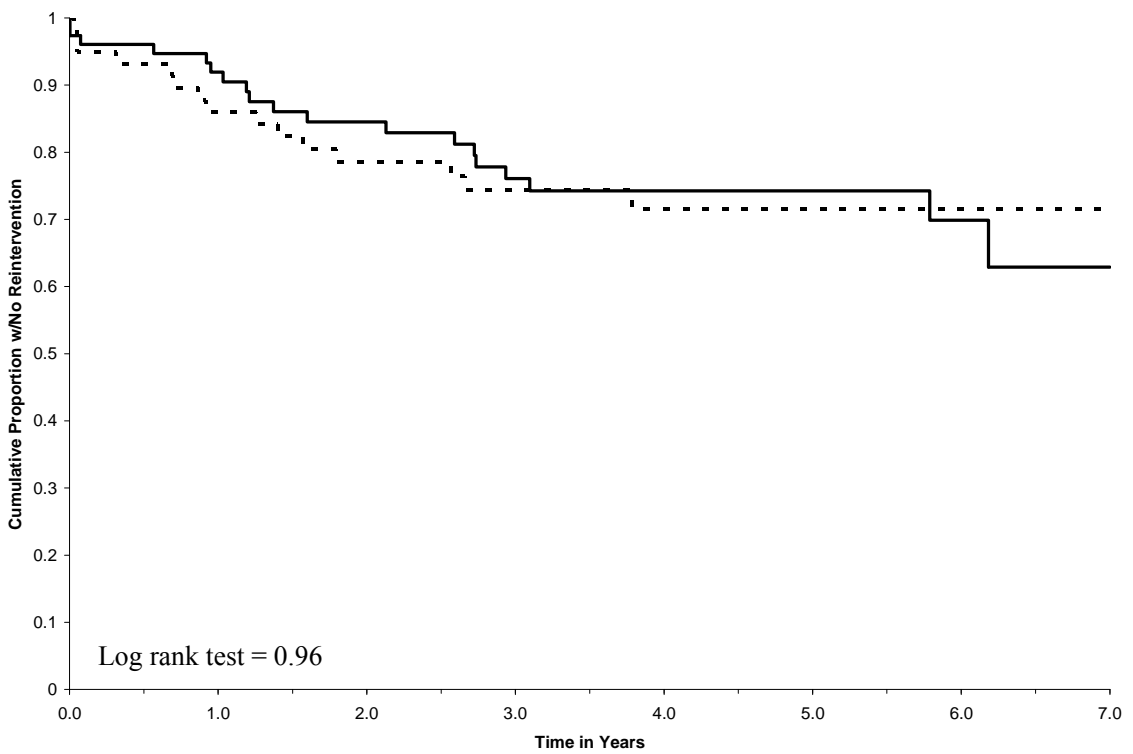

Fig 3: Reintervention for patients living outside a 100mi radius of Albuquerque (solid line) vs. those living within a 100mi radius of Albuquerque (dashed line)

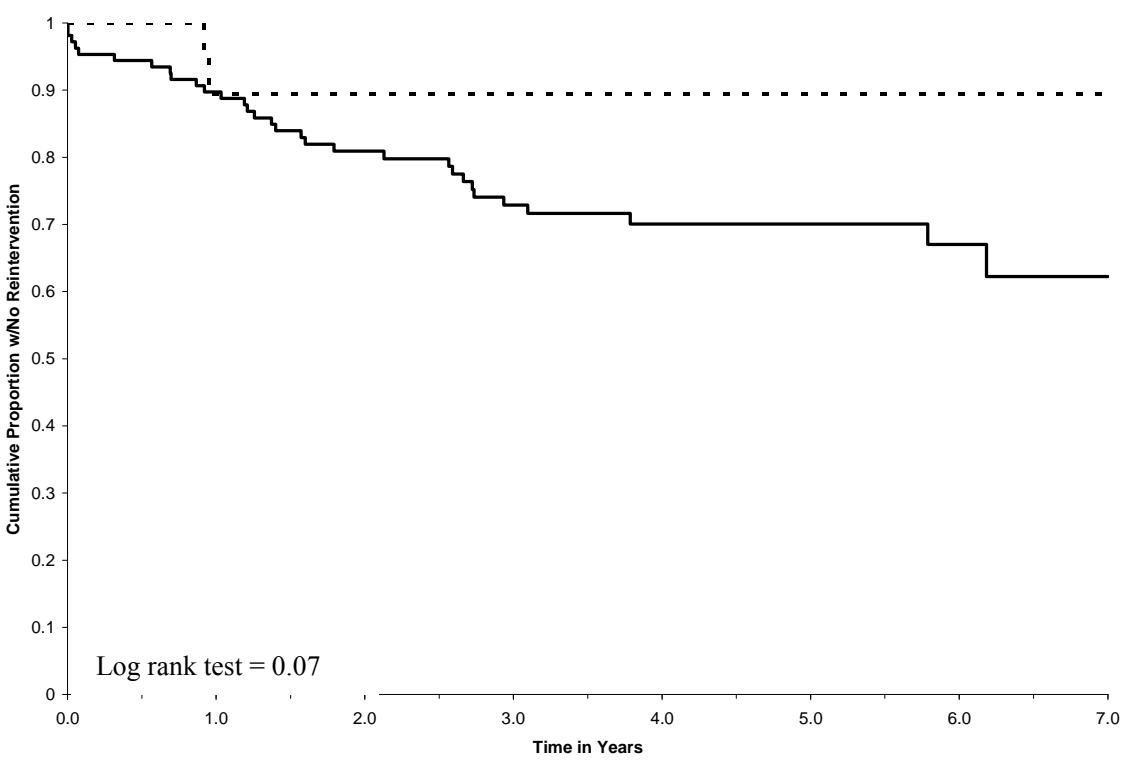

Fig 4: Reintervention for patients with frequent follow-up (solid line) vs. those with incomplete follow-up (dashed line) 
of major complication was greater in the group living outside a $100 \mathrm{mi}$ radius of Albuquerque compared to those living within the radius though this was not statistically significant at $11.8 \%(\mathrm{n}=9)$ vs. $5.0 \%(\mathrm{n}=3 ; \mathrm{P}=0.23)$. Comparing the outcomes of patients with incomplete follow-up and frequent follow-up, no statistical difference was found in survival (Fig 2) or rate of reintervention (Fig 4). The incidence of major complication or conversion to open repair, was similar in both groups, at $10.5 \%(\mathrm{n}=10)$ for the frequent follow-up group vs. $9.3 \%(\mathrm{n}=2 ; \mathrm{P}=1.0)$ for the incomplete follow-up group. The two patients who required open repair in the incomplete follow-up group both lived outside a $100 \mathrm{mi}$ radius of Albuquerque at 334 miles and 502 miles.

\section{DISCUSSION}

EVAR has increasingly become the operation of choice to treat AAA's due to benefits in peri-operative mortality, shorter hospital stays and decreased morbidity. ${ }^{3-8}$ Despite these benefits, EVAR has not been shown to be superior to open repair in terms of long-term AAA-related mortality, perceived patient quality of life and healthcare costs. ${ }^{9-15}$ Additionally, EVAR patients are more likely to suffer from long-term complications, such as endoleak, graft migration and increasing aneurysmal size, thus necessitating life-time follow-up with radiologic imaging for these patients. ${ }^{16-18}$

Though EVAR and open repair have been shown to achieve comparable long-term outcomes in clinical trials, these results are achieved with resources that may not be available to a community surgeon in private practice. Even with these resources, clinical trials such as the European Collaborators on Stent-Graft Techniques for AAA and Thoracic Aortic Aneurysm and Dissection Repair (EUROSTAR) trial, a large multi-center study of 4433 patients, have reported percentages as high as $35 \%$ of patients not completing all scheduled appointments. ${ }^{22}$

Recently, a study by Jones et al. comparing the outcomes of patients in industry sponsored clinical trials with non-study patients has shown no difference in patient survival and reintervention rate. ${ }^{19}$ Similar to the EUROSTAR trial, this study reported that $33 \%$ of EVAR patients had incomplete followup. Data from this study has also demonstrated that post-EVAR patients with incomplete follow-up have higher fatal complication rates than patients with frequent follow-up. This study suggests it is imperative to understand the determinants of consistent patient adherence to follow-up regimens in order to improve EVAR patient outcomes.

One area of concern at the Albuquerque VAMC is the distance patients have to travel for follow-up appointments. The Albuquerque VAMC is a tertiary care facility with a large catchment area, serving veterans in New Mexico, east Texas, southern Colorado and western Arizona. With at least six months between each appointment and possibly hundreds of miles to travel, several barriers exist to patient adherence to follow-up appointments. Based on these factors and on literature review, we formed three hypotheses:

- Follow-up adherence post-EVAR is superior for patients living close to the VAMC than for those traveling long distances.

- Outcomes for patients with incomplete follow-up are inferior to patients with complete follow-up.

- Outcomes for patients living within $100 \mathrm{mi}$ of Albuquerque are better than for patients living outside of this radius.

In reviewing the first hypothesis, we found no significant difference in follow-up adherence for patients living within a 100mi radius of Albuquerque versus those living outside this radius. Like the determinants of adherence, we believe the reasons behind this result are multifactorial. First, we believe the 
national VAMC network is an ideal system for follow-up of EVAR patients regardless of their distance from a tertiary care facility because it eliminates many of the barriers to patient adherence. One major advantage to this system is an electronic database, which can track patients at any facility in the country. Factors, such as notes left on the system to contact the Albuquerque VAMC should any other VAMC make contact with the patient, likely contribute to improved patient follow-up. Another possible reason why distance did not significantly affect the follow-up adherence is that once patients are plugged into the VAMC system in terms of benefits, their healthcare costs are covered in ways that patients in the general public are not. This eliminates yet another stressor that impedes patient adherence. Lastly, the VAMC is a national system, making it easier for a patient to be seen anywhere in the country; once a patient is seen, providers are able to look at notes in the electronic database and encourage patients to attend their missed appointments. Of the 19 patients in the infrequent follow-up group at the Albuquerque VAMC, only 5 were not actually seen at another VAMC.

In examining the second hypothesis we demonstrated no difference in survival or reintervention rate for patients with frequent or incomplete follow-up. Because only $15 \%$ of patients experienced incomplete follow-up, we believe our sample size was too small to discern a difference in outcomes. In fact, patients had longer follow-up times in the infrequent follow-up group than in the frequent follow-up group. This may be due to our inability to re-establish contact with five of the 19 patients in this group and our assumption then that these five patients are alive and well. In actuality, given that $40.4 \%$ of patients in the study died during the study period from all-cause mortality, some of these patients were likely deceased and may have made a difference in the survival and reintervention rate of the infrequent follow-up group. Another reason why the follow-up time was longer for infrequent follow-up patients was due to the fact that most of these patients had EVAR in 2000-2002 and none in 20052006, while the frequent follow-up patients were evenly distributed in time. In other words, EVAR's performed in more recent years likely artificially lowered the follow-up time for the frequent follow-up patients.

Looking at the third hypothesis we found no difference in survival or reintervention rate for patients living within a 100mi radius of Albuquerque compared to those living outside this radius. This concurs with our analyses that there was no difference in the degree of follow-up between these two groups.

Overall, these results suggest that distance from a tertiary care center is not a limiting factor in patient adherence to follow-up protocols. In addition, the VA medical system is equipped with a comprehensive electronic records database and fewer economic barriers for patients to obtain healthcare. Our study also implies that such a system can much improve follow-up in EVAR patients. We achieved a percentage of patients with incomplete follow-up that is less than half of the rate published in current literature. Interestingly, this did not translate to improved patient outcomes, though this may be due to a sicker veteran population compared to the general public. ${ }^{23}$

Our study has both strong points and limitations in methodology. One of the strengths of this paper is the long duration of study, with median follow-up time at over four years. Only two patients of the 34 who required reintervention had a secondary procedure done at greater than four years from the initial EVAR and no patients who expired from a AAA-related cause died later than four years from the initial EVAR. This suggests that the study was conducted for a sufficient duration of time as to discover most of the outcomes data. Furthermore, at the conclusion of this study, all patients were at least one year 
out from the date of the initial EVAR procedure. This is significant because our definition of infrequent follow-up required patients to miss greater than two appointments which was not possible within a one year period (one month and six month appointments); in other words, if our study had included patients who were less than one year out from EVAR, the number of patients in the frequent follow-up group would be falsely elevated. Another asset to this study is the dedicated nurse who vigilantly and persistently followed patients, regardless of whether they were enrolled in a clinical trial until absolutely all methods of contact were exhausted. This likely contributed to the lower percentage of patients in the infrequent follow-up group.

Potential limitations of this study include the biases inherent in retrospective studies and the low sample size which may contribute to type II statistical errors. We assumed the data in the VAMC system was up to date and complete in terms of outcomes, and therefore did not attempt to re-establish direct contact with the patients in the infrequent follow-up group or seek other means of determining their mortality status (i.e. mortality databases, obituaries, etc.), which could also be a limitation. Lastly, the results obtained were relevant for a veteran population and may not apply to the general patient population. Further studies on the determinants for poor patient adherence to follow-up protocols and the impact of follow-up on patient outcomes should be conducted at other institutions to corroborate our findings.

\section{CONCLUSION}

At the Albuquerque VAMC, one in seven EVAR patients have incomplete follow-up. Moreover, even though more than half of our patient population lives outside a $100 \mathrm{mi}$ radius of the VAMC, no difference was found in follow-up adherence between these two groups. Consequently, no difference in outcomes was demonstrated based on patient follow-up status or distance from the tertiary care center. This suggests that patients can be safely treated for EVAR at tertiary care centers which are a long distance from home, and achieve reliable follow-up. Additional studies evaluating the potential barriers against patient adherence to follow-up regimens are needed in order to help in the selection of good candidates for EVAR.

\section{REFERENCES}

1. Parodi JC, Palmaz JC, Barone HD. Transfemoral intraluminal graft implantation for abdominal aortic aneurysms. Ann Vasc Surg. 1991;5:491-499.

2. Veith FJ, Marin ML, Cynamon J, Schonholz C, Parodi J. 1992: Parodi, Montefiore, and the first abdominal aortic aneurysm stent graft in the United States. Ann Vasc Surg. 2005;19:749-751.

3. Bush RL, Johnson ML, Collins TC, et al. Open versus endovascular abdominal aortic aneurysm repair in VA hospitals. $J$ Am Coll Surg. 2006;202:577-587.

4. Bush RL, Johnson ML, Hedayati N, Henderson WG, Lin PH, Lumsden AB. Performance of endovascular aortic aneurysm repair in high-risk patients: Results from the veterans affairs national surgical quality improvement program. J Vasc Surg. 2007;45:227-233; discussion 233-5.

5. Chahwan S, Comerota AJ, Pigott JP, Scheuermann BW, Burrow J, Wojnarowski D. Elective treatment of abdominal aortic aneurysm with endovascular or open repair: The first decade. J Vasc Surg. 2007;45:258-62; discussion 262.

6. Dillavou ED, Muluk SC, Makaroun MS. Improving aneurysm-related outcomes: Nationwide benefits of endovascular repair. J Vasc Surg. 2006;43:446-51; discussion 451-2.

7. Greenhalgh RM, Brown LC, Kwong GP, Powell JT, Thompson SG, EVAR trial participants. Comparison of endovascular aneurysm repair with open repair in patients with abdominal aortic aneurysm (EVAR trial 1), 30-day operative mortality results: Randomised controlled trial. Lancet. 2004;364:843-848.

8. Lee WA, Carter JW, Upchurch G, Seeger JM, Huber TS. Perioperative outcomes after open and endovascular repair of intact abdominal aortic aneurysms in the United States during 2001. J Vasc Surg. 2004;39:491-496.

9. Aljabri B, Al Wahaibi K, Abner D, et al. Patientreported quality of life after abdominal aortic aneurysm surgery: A prospective comparison of endovascular and open repair. $J$ Vasc Surg. 2006;44:1182-1187. 
10. EVAR trial participants. Endovascular aneurysm repair versus open repair in patients with abdominal aortic aneurysm (EVAR trial 1): Randomised controlled trial. Lancet. 2005;365:2179-2186.

11. EVAR trial participants. Endovascular aneurysm repair and outcome in patients unfit for open repair of abdominal aortic aneurysm (EVAR trial 2): Randomised controlled trial. Lancet. 2005;365:2187-2192.

12. Lottman PE, Laheij RJ, Cuypers PW, Bender M, Buth J. Health-related quality of life outcomes following elective open or endovascular AAA repair: A randomized controlled trial. J Endovasc Ther. 2004;11:323-329.

13. Prinssen M, Buskens E, de Jong SE, et al. Costeffectiveness of conventional and endovascular repair of abdominal aortic aneurysms: Results of a randomized trial. J Vasc Surg. 2007;46:883-890.

14. Soulez G, Therasse E, Monfared AA, et al. Pain and quality of life assessment after endovascular versus open repair of abdominal aortic aneurysms in patients at low risk. J Vasc Interv Radiol. 2005;16:1093-1100.

15. Wilt TJ, Lederle FA, Macdonald R, Jonk YC, Rector TS, Kane RL. Comparison of endovascular and open surgical repairs for abdominal aortic aneurysm. Evid Rep Technol Assess (Full Rep). 2006;(144):1-113.

16. Cao P, Verzini F, Parlani G, et al. Clinical effect of abdominal aortic aneurysm endografting: 7-year concurrent comparison with open repair. J Vasc Surg. 2004;40:841-848.

17. Eliason JL, Wainess RM, Dimick JB, et al. The effect of secondary operations on mortality following abdominal aortic aneurysm repair in the United States: 1988-2001. Vasc Endovascular Surg. 2005;39:465-472.

18. Hobo R, Buth J, EUROSTAR collaborators. Secondary interventions following endovascular abdominal aortic aneurysm repair using current endografts. A EUROSTAR report. J Vasc Surg. 2006;43:896-902.

19. Jones WB, Taylor SM, Kalbaugh CA, et al. Lost to follow-up: A potential under-appreciated limitation of endovascular aneurysm repair. J Vasc Surg. 2007;46:434-40; discussion 440-1.

20. Griffith S. A review of the factors associated with patient compliance and the taking of prescribed medicines. Br J Gen Pract. 1990;40:114-116.

21. Jacobson JA. The effect of patients' noncompliance on their surgeons' obligations. Surg Clin North Am. 2007;87:937-48, viii.

22. Leurs LJ, Laheij RJ, Buth J, EUROSTAR Collaborators. What determines and are the consequences of surveillance intensity after endovascular abdominal aortic aneurysm repair? Ann Vasc Surg. 2005;19:868-875.

23. Weiss JS, Dumas P, Cha C, Gusberg RJ, Dardik A. Safety of carotid endarterectomy in a high-risk population: Lessons from the VA and Connecticut. J Am Coll Surg. 2006;203:277-282. 